\title{
Note on Abbreviations
}

Abbreviations for ancient sources and reference works follow the third edition of the Oxford Classical Dictionary. 
